Artículo Original. Mayo-Agosto 2017; 7(2):68-74. Recibido: 07/12/2016 Aceptado: 10/07/2017.

http://dx.doi.org/10.21929/abavet2017.72.6

\title{
Efecto de la humedad en incubación sobre la incubabilidad y mortalidad embrionaria del pollo de engorda en el trópico seco mexicano
}

\author{
Effect of incubator relative humidity on hatchability and embryonic mortality of broiler \\ chicken in Mexican dry tropic
}

\section{Prado-Rebolledo Omar*1 omarpr@ucol.mx; Juárez-Estrada Marco² britoco@unam.mx}

${ }^{1}$ Facultad de Medicina Veterinaria y Zootecnia, Universidad de Colima, México. ${ }^{2}$ Facultad de Medicina Veterinaria y Zootecnia. Universidad Nacional Autónoma de México. *Autor responsable y de correspondencia: Prado-Rebolledo Omar. Facultad de Medicina Veterinaria y Zootecnia, Universidad de Colima, México. Autopista Colima-Manzanillo km. 40. Crucero de Tecomán, Colima. C.P 28100.

\section{RESUMEN}

El objetivo del presente experimento fue evaluar el efecto de dos humedades relativas (HR) en incubación sobre la incubabilidad y mortalidad embrionaria del pollo de engorda en trópico seco mexicano. Un total de 2,520 huevos fértiles incubables fueron divididos en dos tratamientos (1,260 huevos/ tratamiento), se colocaron en bandejas y se precalentaron. Los tratamientos se mantuvieron con $50 \pm 2 \%$, y $58 \pm 2 \% \mathrm{HR}$. Se mantuvo la temperatura de ambas incubadoras a $37.7^{\circ} \mathrm{C}$. Estas condiciones prevalecieron desde el día 0 hasta el día 19 de incubación. La pérdida de peso fue más significativa $(\mathrm{P}<0.05)$ con $50 \%$ HR que a 58 $\% \mathrm{HR}$. El peso corporal e incubabilidad no se afectaron por la HR. La mortalidad embrionaria tuvo diferencias significativas en la primera semana con un aumento en la HR de $50 \%$, en las posteriores etapas de mortalidad embrionaria fueron iguales $(P>0.05)$ a ambas $H R$. La pérdida de peso fue mayor con la $H R$ de $50 \%$. Se concluye que ambas HR se pueden usar en incubación sin afectar la eclosión.

Palabras clave: Incubabilidad, incubación, humedad relativa, mortalidad embrionaria.

\begin{abstract}
The objective of this experiment was to evaluate the effect of two relative humidities $(\mathrm{RH})$ in incubator machine over hatchability and embryonic mortality of broiler chicken in Mexican dry tropics. A total of 2,520 incubating eggs were warmed at room temperature, they were weighed each one and divided into treatments $(1,260$ eggs/each) placed in trays and preheated. These treatments were maintained with $\mathrm{RH}$ to $50 \pm 2 \%$ and the other $\mathrm{RH}$ of $58 \pm 2 \%$. The temperature in both incubators was kept at $37.7^{\circ} \mathrm{C}$. These conditions prevailed from day 0 until day 19 of incubation. Weight loss was more significant $(\mathrm{P}<0.05)$, with $50 \% \mathrm{RH}$ than $58 \% \mathrm{RH}$. Body weight and hatchability were no affected by incubation $\mathrm{RH}$. The data of embryo mortality had a significant difference in the first week with $50 \%$ of $\mathrm{RH}$, the other stage of embryonic mortality was equal $(\mathrm{P}>0.05)$ with both $\mathrm{RH}$ incubation. The eggs incubated at $50 \% \mathrm{RH}$ had increased weight loss in comparison with the other incubation $\mathrm{RH}$. It is concluded that both $\mathrm{HR}$ can be used without affecting incubating hatching.
\end{abstract}

Keyword: Hatchability, incubation, relative humidity, embryo mortality. 


\section{INTRODUCCIÓN}

El manejo de los huevos fértiles desde la granja a la planta continúa siendo esencialmente el mismo, se recolectan de los nidos varias veces al día para evitar su ruptura y contaminación bacteriana, una vez colectados los huevos son puestos a enfriar aproximadamente de 15 a $20{ }^{\circ} \mathrm{C}$ y 75 a $80 \%$ de humedad; los huevos pueden ser desinfectados y almacenados postcolecta, y son enfriados por aproximadamente tres días. La transportación de los huevos en camiones de ambiente controlado no ocurre diariamente, ya que las distancias de la granja a la planta incubadora son considerables y puede ser económicamente ineficiente. Los huevos son transportados a las plantas incubadoras, donde son colocados en un cuarto frío con temperatura y humedad regulada, por lo que el tiempo de almacenamiento varía dependiendo la situación de demanda de la industria del pollo de engorda y planta incubadora. La mayoría de las plantas incubadoras comerciales modernas cuentan con incubadoras multietapas, así que la eficiencia de la operación de la incubadora es afectada por su capacidad y programación de carga (Fasenko 2007).

La temperatura, humedad, ventilación y volteo de los huevos son fundamentales en el proceso de incubación, generalmente se acepta que $37.7^{\circ} \mathrm{C}$, sea una temperatura promedio viable, tanto para los pollos como para los pavos. Por arriba o debajo de este punto, la viabilidad del embrión se puede ver disminuida y el porcentaje de nacimientos reducido (Michels, et al; 1974; Meijerhof, 1992; Decuypere et al; 1992; Phillips, et al, 1992; Suárez et al; 1997; French, 1997; Taylor, 1997; Peebles, et al; 2001.

El nacimiento de los pollos y el procesado posterior son cruciales para el desempeño productivo de las aves. Las aves de producción son los únicos animales que se transportan una vez que eclosionan, lo que hace que sea una experiencia importante en la vida de las aves. Comúnmente se les llama "Pollos de un día", pero en realidad pueden tener hasta tres días de edad, debido al tiempo de eclosión desde el primer pollo hasta el último, que va de 24 a 48 h (Jacobs, et al; 2016).

Uno de los subproductos del metabolismo que ocurre durante la incubación es el agua; el embrión debe eliminar el exceso de agua para poder eclosionar. Durante la incubación un huevo pierde peso debido a la evaporación de agua; esta pérdida de peso es esencial para crear una suficiente cámara de aire que permita la ventilación pulmonar embrionaria, después del picado interno y una exitosa eclosión. Una alta tasa de eclosión es alcanzada cuando exista una pérdida de agua de 12 a $14 \%$ del peso del huevo al momento de incubar, hasta el momento de la transferencia (Taylor, 1997; Barbosa, et al; 2012; Van der Pol, et al; 2013). Con el fin de regular la evaporación del agua del huevo, debe controlarse el contenido de humedad relativa exterior (Decuypere y Michels, 1992; Phillips, et al; 1992). 
Burh (1995) realizó un estudio donde evaluó el efecto de diferentes humedades relativas en incubación sobre la incubabilidad, volumen de fluido alantoideo y peso del embrión; donde no encontró diferencias estadísticas en la incubabilidad en las diferentes humedades empleadas, y la pérdida de peso de los huevos se incrementó al elevar la humedad en incubación; el volumen del fluido alantoideo se incrementó conforme aumentaba la humedad. Por otro lado, está bien documentado que conforme aumenta la edad de la reproductora, el cascarón se vuelve más poroso, por lo que incrementa la pérdida de peso del huevo, afectando el intercambio gaseoso del embrión (Scott, 1999; Wilson, 1991; Burh, 1995; Peebles, et al; 1987, Vick, 1993).

La temperatura de bulbo húmedo y seco, son dos variables provistas en las incubadoras modernas y son fácilmente manipulables. La relación entre estas dos humedades determina la humedad relativa (HR). La HR externa tiene gran influencia sobre la pérdida de agua durante el proceso de incubación. En México existen zonas geográficas con alta HR, como resultado de este factor, se puede llegar a afectar la incubabilidad y calidad del pollo.

Por lo antes expuesto, descrito el objetivo del presente trabajo, que es determinar el efecto de la humedad durante el proceso de incubación, sobre la pérdida de humedad, incubabilidad y mortalidad embrionaria en época de verano.

\section{MATERIAL Y MÉTODOS}

Se utilizaron 2,520 huevos fértiles, aptos para incubar de la estirpe Ross $x$ Ross con 38 semanas de edad; se identificaron y clasificaron por peso, los cuales previamente antes de incubar se precalentaron por un periodo de 10 horas, a una temperatura promedio de $32{ }^{\circ} \mathrm{C}$, con $60 \%$ humedad relativa (HR). Los huevos se distribuyeron en dos tratamientos con tres repeticiones de 420 huevos en dos máquinas incubadoras. Todos los huevos residuales se examinaron macroscópicamente para determinar la posible causa de mortalidad embrionaria; los huevos se clasificaron como: infértiles, mortalidad temprana (1 a 7 días), mortalidad intermedia (8 a 13 días), mortalidad tardía (14 a 20 días) y huevo picado pero que no eclosionó. Las variables de respuesta a considerar fueron: peso del huevo al momento de la transferencia, peso del pollito al nacer, porcentaje de incubabilidad y mortalidad embrionaria. Los datos se sometieron a un Análisis de Varianza (ANDEVA). Para las diferencias entre tratamientos, se utilizó la prueba de Tukey $(\mathrm{P}<0.05)$. Los porcentajes de los datos se analizaron previa transformación al arco seno (Steel y Torrie, 1981). Los datos se realizaron utilizando el paquete computacional Statistix for Windows 2.0. 1985 (Microsoft ${ }^{\circledR}$ ).

\section{RESULTADOS}

La pérdida de humedad durante el proceso de incubación mostró diferencia estadística 
entre los tratamientos, resultando con mayor pérdida el tratamiento con $50 \%$ de $\mathrm{HR}$, con una diferencia de $0.78 \%$; el peso de los pollos al nacimiento y porcentaje de incubabilidad no mostraron significancia entre tratamientos. Los huevos residuales se clasificaron de acuerdo a la etapa de muerte embrionaria, la cual sólo mostró diferencia significativa en la primera etapa de desarrollo embrionario; las posteriores etapas fueron iguales estadísticamente $(\mathrm{P}<0.05)$ como se puede apreciar en el Cuadro 1.

\begin{tabular}{|c|c|c|c|c|c|c|c|}
\hline \multirow{2}{*}{ Tratamiento } & \multirow{2}{*}{$\begin{array}{l}\text { Pérdida de } \\
\text { humedad }\end{array}$} & \multirow{2}{*}{ Peso (g) } & \multirow{2}{*}{ Incubabilidad } & \multicolumn{4}{|c|}{ Mortalidad embrionaria } \\
\hline & & & & 1-7 días & 8-13 días & 14-20 días & Picado \\
\hline $1(50 \%$ HR) & $11.43 \pm 3.85^{\mathrm{a}}$ & $42.97 \pm 3.49^{a}$ & $86.51 \pm 2.95^{\mathrm{a}}$ & $8.49 \pm 3.4^{\mathrm{a}}$ & $3.33 \pm 2.7^{a}$ & $2.00 \pm 1.7^{\mathrm{a}}$ & $1.67 \pm 1.0^{\mathrm{a}}$ \\
\hline $2(58 \%$ HR) & $10.65 \pm 3.82^{b}$ & $42.85 \pm 3.47^{a}$ & $86.82 \pm 0.66^{a}$ & $6.10 \pm 4.2^{b}$ & $4.33 \pm 1.30^{\mathrm{a}}$ & $1.33 \pm 0.3^{a}$ & $1.33 \pm 0.9^{a}$ \\
\hline
\end{tabular}

Cuadro 1. Efecto de dos HR en incubación sobre las variables de incubación

\section{DISCUSIÓN}

El presente estudio mostró que la pérdida de humedad es afectada al manipular la temperatura de bulbo húmedo, ya que se incrementó significativamente en $50 \% \mathrm{HR}$ con respecto a $58 \% \mathrm{HR}$. Los huevos deben de perder alrededor de 11 a $14 \%$ de su peso original durante el proceso de incubación (Peebles et al, 2001; Suarez et al 1997; Decuypere y Michels 1992; Buhr, 1995; Prado et al 2001). La cutícula ha sido caracterizada como la barrera más externa del huevo para el control de microorganismos ambientales y el intercambio gaseoso y pérdida de agua, a través de los poros durante el desarrollo embrionario (Vick et al 1993; Nys et al, 1999). También se ha demostrado que, si se remueve la cutícula, incrementa la pérdida de vapor de agua por conductancia; esto sugiere que la cutícula juega un papel importante en la regulación de la pérdida de peso del huevo en incubación (Suarez et al, 1997; Peebles et al, 1987, Vick et al 1993; Peebles y Brake, 1987).

El peso de los pollos al nacimiento no mostró diferencia entre tratamiento, esto pudo ser a que ambos tratamientos provenían de la misma edad de reproductora; aunque guarda una relación directa con el peso del huevo y peso del saco vitelino (Barbosa, et al, 2012; Suárez et al; 1997, Wilson, 1991; Narahara et al, 2000). La edad de la reproductora afecta la incubabilidad, por lo que se tiene una relación lineal positiva conforme aumenta la edad de la reproductora y hay un aumento del tamaño del huevo, peso del pollo; más sin embargo hay una correlación lineal negativa entre la edad de la reproductora y la incubabilidad. 
En el presente estudio no se observó diferencia significativa, ya que se utilizó únicamente una edad de reproductora, sin que se afectara por la temperatura de bulbo húmedo (Barbosa et al; 2012, French, 1997, Michels et al; 1974; Fasenko et al; 2001, Wilson, 1991; Burh, 1995; Vick et al; 1993; Arce, 1998). Aunque en el presente estudio no mostró diferencia significativa entre los tratamientos en las variables de mortalidad embrionaria, se puede apreciar que hay un aumento considerable de mortalidad embrionaria en los primeros días de incubación, puede ser asociado a las condiciones del manejo de todos los huevos en general, ya que la granja de reproductora se localiza a una distancia de 1 000 kilómetros de retirada de la planta incubadora; por lo que el transporte puede estar influyendo de manera significativa. Por otro lado, puede ser que el blastodermo se mueva por una rotura de la chalaza y cambia la posición de la yema y blastodermo, ocasionando la muerte embrionaria durante los primeros días de incubación (Peebles et al; 1987; Vick, et al; 1993; Ulmer-Franco, et al, 2010.). Estos resultados sugieren que, al manipular la temperatura de bulbo húmedo, en lugares donde la humedad ambiental es alta o en época de verano, se pueden controlar de manera más apropiada la pérdida de peso de los huevos durante el proceso de incubación.

\section{LITERATURA CITADA}

BARBOSA VM, Rocha JSR, Pompeu MA, Martins NRS, Baiâ NC, Lara LJC, Batista JVMSP, Leite RC. 2012. The effects of relative humidity and turning in incubators machines on the incubation yield and chick performance. World's Poultry Science Journal: 69; 89-98. ISSN: 0043-9339 DOI: https://doi.org/10.1017/S0043933913000081.

BUHR RJ. 1995. Incubation relative humidity effects on allantoic fluid volume and hatchability. Poultry Science. 74:874-884. ISSN: 0032-5791. ISSN: 0032-5791. DOI:

https://doi.org/10.3382/ps.0740874

DECUYPERE E, Michels H. 1992. Incubation temperature as a management tool: a review. World's Poultry Science Journal. 48:28-38. ISSN: 0043-9339. DOI: https://doi.org/10.1079/WPS19920004

FASENKO GM. 2007. Egg storage and the embryo. Poultry Science. 86:1020,1024. ISSN: 0032-5791. DOI: https://doi.org/10.1093/ps/86.5.1020.

FASENKO GM, Christensen VI, Wineland MJ, Petite N. 2001. Examining the effects of prestorage incubation of turkey breeder eggs on embryonic development and hatchability of eggs stored for four or fourteen days. Poultry Science. 80:132-138. ISSN: 0032-5791. DOI: https://doi.org/10.1093/ps/80.2.132. 
FRENCH NA. 1997. Modeling incubation temperature: The effects of incubation design embryonic development, and egg size. Poultry Science. 76:124-133. ISSN: 0032-5791 DOI: https://doi.org/10.1093/ps/76.1.124.

JACOBS L, Delezie E, Duchateau L, Goethals K, Ampe B, Lambrecht E, Gellynck X, Tuyttens FAM. 2016. Effect of post-hatch transportation duration and parental age on broiler chicken quality, welfare, and productivity. Poultry Science.95:1973-1979. ISSN. 0032-5791. DOl:https://doi.org/10.3382/ps/pew155.

MEIJERHOF R.1992. Pre-incubation holding of hatching eggs. World's Poultry Science Journal. 48:57-68. ISSN: 0043-9339. DOI: https://doi.org/10.1079/WPS19920006

MICHELS H, Geers R, Muambi S. 1974. The effect of incubation temperature on pre and hatching development in chickens. British Poultry Science. 15:517-523. ISSN: 0007-1668. DOI: $10.1080 / 00071667408416142$.

NARAHARA D, Asha Rajin R, Srinivasan G, Ramamurthy N. 2000. Methods to improve the hatchability of checked chicken eggs. British Poultry Science. 178-181. ISSN: 00071668. DOI: $10.1080 / 713654922$.

NYS Y, Hincke MT, Arias JL, García-Ruiz JM, Solomon SE. 1999. Avian eggshell mineralization. Poultry and Avian Biology Reviews. 10(3); 143-166. Issn: 1470-2061. DOI: https://www.researchgate.net/publication/279562431

PEEBLES ED, Brake J, Gildersleeve RP. 1987. Effects of eggshell cuticle removal and incubation humidity on embryonic development and hatchability of broiler. Poultry Science 66:834-840. ISSN: 0032-5791. DOI: https://doi.org/10.3382/ps.0660834.

PEEBLES ED, Brake J. 1987. Eggshell quality and hatchability in broiler eggs. Poultry Science. 66:596-604. ISSN: 0032-5791 DOI: https://doi.org/10.3382/ps.0660596.

PEEBLES ED. Doyle SM, Zuwalt CD, Gerard PD, Latour MA, Boyle CR, Smith TW. 2001. Breeder age influences embryogenesis in broiler eggs. Poultry Science. 80:272-277. ISSN: 0032-5791. DOI: https://doi.org/10.1093/ps/80.3.272.

PHILLIPS L, Brake J, Ellner S, Oukama R.1992. A mathematical model for estimation of broiler egg weight loss from physical dimensions and air cell size during incubation. Poultry Science. 71:625-630. ISSN: 0032-5791. DOI: https://doi.org/10.3382/ps.0710625.

SCOTT M. 1999. Embriodiagnóstico. (Principales problemas de incubación). Primera Convención Nacional AVECA-G. Manzanillo, Colima, México. 21-23 de octubre.

STATISTIX for Windows 2.0. 1985 (Microsoft @). Analytical Software P.O. Box 12185. Tallahassee FL 3217-2185. Disponible: https://www.statistix.com 
Steel RGD, Torrie JH. 1981. Principles and procedures of Statistix. A biometrical approach. 2nd ed. Singapure: McGraw-Hill. 633 p. ISBN: $0070609268,9780070609266$.

SUÁREZ ME, Wilson HR, Mather FB, Wilcox CJ, Mepherson BN. 1997. Effect of strain and age of the broiler breeder female on incubation time and chick weight. Poultry Science. 76:1029-1036. ISSN: 0032-5791. DOI: https://doi.org/10.1093/ps/76.7.1029.

TAYLOR G. 1997. Humedad y pérdida de peso del huevo durante incubación. Boletín de Chick Master Incubator Company.

ULMER-FRANCO AM, Fasenko GM, O'Dea CEE. 2010. Hatching egg characteristics, chick quality, and broiler performance at 2 breeder flock ages and from 3 egg weights. Poultry Science. 89:2735-2742. ISSN: 0032-5791. DOI: https://doi.org/10.3382/ps.200900403.

VAN der Pol C., Roovert-Reijink van IAm, Maatjens CM, Brand van den $\mathrm{H}$, Molenaar R. 2013. Effect of relative humidity during incubation at a set eggshell temperatura and brooding temperature posthatch on embryonic mortality and chick quality. Poultry Science. 92:2145-2155. ISSN: 0032-5791. DOI: 10.3382/ps.2013-03006.

VICK SV, Brake J, Walsh TJ. 1993. Relationship of incubation humidity and flock age to hatchability of broiler hatching eggs. Poultry Science. 72:251-258. ISSN. 0032-5791. DOI: https://doi.org/10.3382/ps.0720251.

WILSON HR. 1991. Interrelationships of egg size, chick size, post hatching growth and hatchability. World's Poultry Science Journal. 47:5-20. ISSN: 0043-9339. DOI: https://doi.org/10.1079/WPS19910002. 